Article

\title{
A Counter-Current Heat-Exchange Reactor for the Thermal Stimulation of Hydrate-Bearing Sediments
}

\section{Judith M. Schicks *, Erik Spangenberg, Ronny Giese, Manja Luzi-Helbing, Mike Priegnitz and Bettina Beeskow-Strauch}

Helmholtz Centre Potsdam GFZ German Research Centre for Geosciences Section 4.2, Telegrafenberg, Potsdam 14473, Germany; E-Mails: erik@gfz-potsdam.de (E.S.); rgiese@gfz-potsdam.de (R.G.); mluzi@gfz-potsdam.de (M.L.-H.); mikep@gfz-potsdam.de (M.P.); betti@gfz-potsdam.de (B.B.-S.)

* Author to whom correspondence should be addressed; E-Mail: schick@gfz-potsdam.de;

Tel.: +49-331-288-1487; Fax: +49-331-288-1474.

Received: 25 March 2013; in revised form: 16 May 2013 / Accepted: 7 June 2013 /

Published: 18 June 2013

\begin{abstract}
Since huge amounts of $\mathrm{CH}_{4}$ are bound in natural gas hydrates occurring at active and passive continental margins and in permafrost regions, the production of natural gas from hydrate-bearing sediments has become of more and more interest. Three different methods to destabilize hydrates and release the $\mathrm{CH}_{4}$ gas are discussed in principle: thermal stimulation, depressurization and chemical stimulation. This study focusses on the thermal stimulation using a counter-current heat-exchange reactor for the in situ combustion of $\mathrm{CH}_{4}$. The principle of in situ combustion as a method for thermal stimulation of hydrate bearing sediments has been introduced and discussed earlier [1,2]. In this study we present the first results of several tests performed in a pilot plant scale using a counter-current heat-exchange reactor. The heat of the flameless, catalytic oxidation of $\mathrm{CH}_{4}$ was used for the decomposition of hydrates in sand within a LArge Reservoir Simulator (LARS). Different catalysts were tested, varying from diverse elements of the platinum group to a universal metal catalyst. The results show differences regarding the conversion rate of $\mathrm{CH}_{4}$ to $\mathrm{CO}_{2}$. The promising results of the latest reactor test, for which LARS was filled with sand and ca. $80 \%$ of the pore space was saturated with $\mathrm{CH}_{4}$ hydrate, are also presented in this study. The data analysis showed that about $15 \%$ of the $\mathrm{CH}_{4}$ gas released from hydrates would have to be used for the successful dissociation of all hydrates in the sediment using thermal stimulation via in situ combustion.
\end{abstract}


Keywords: thermal stimulation; in situ combustion; gas production; counter-current heat-exchange reactor

\section{Introduction}

Clathrate hydrates are ice-like solids composed of a three-dimensional network of hydrogen-bonded water molecules that confines gas molecules in well-defined cavities of different sizes. Natural gas hydrates contain predominantly $\mathrm{CH}_{4}$, but-depending on the gas source - they may also contain lighter hydrocarbons or $\mathrm{CO}_{2}$ and $\mathrm{H}_{2} \mathrm{~S}$. In general, gas hydrates form in the presence of sufficient amounts of gas and water and at low temperatures and elevated pressures [3]. Natural gas hydrates have therefore been found at all active and passive continental margins as well as permafrost regions and in locations with similar conditions [4]. Their widespread global occurrence and the fact that $1 \mathrm{~m}^{3}$ of gas hydrate can contain up to $172 \mathrm{~m}^{3}$ of natural gas at standard conditions, has led to the assumption that enormous amounts of $\mathrm{CH}_{4}$ and lighter hydrocarbons are stored in hydrate-bearing sediments. Thus, natural gas hydrates have become more and more attractive as a potential future energy resource. However, the production of $\mathrm{CH}_{4}$ from hydrate-bearing sediments is still a technical challenge. In order to release gas from hydrate-bearing sediments it is necessary to decompose the embedded gas hydrate. In principle, this can be realized by distortion of the mechanical equilibrium (pressure reduction), thermal equilibrium (heating) or chemical equilibrium (e.g., injection of inhibitors or $\mathrm{CO}_{2}$ ). In this study, we will focus on the thermal stimulation method, which was already tested successfully in a field test in the framework of the Mallik Scientific Drilling Project in the Northwest Territories in the Canadian Arctic during the winter of 2001/2002. During this gas production test a hot fluid was pumped through about $600 \mathrm{~m}$ of permafrost into depths of 900-1100 m where the hydrate-bearing sediment occurred. Some $470 \mathrm{~m}^{3}$ (surface conditions) of $\mathrm{CH}_{4}$ were produced from dissociated hydrates within $123.7 \mathrm{~h}$ [5]. This test was certainly successful in terms of demonstrating the possibility of producing $\mathrm{CH}_{4}$ from hydrate-bearing sediments using thermal stimulation, but the efficiency of this method remains questionable. The loss of heat during the hot fluid transport through hundreds of meters of permafrost, the mild heating treatment and thus the comparatively minor radial propagation of heat in the hydrate layer indicate that this procedure is probably not efficient enough for commercial gas production. An alternative method to thermal stimulation via hot fluid circulation may be in situ combustion of $\mathrm{CH}_{4}$ in a counter-current heat-exchange reactor. The principle of in situ combustion as a method for thermal stimulation of hydrate bearing sediments has been introduced and discussed earlier [1,2]. The striking advantage of using thermal stimulation via in situ combustion for the gas production from natural gas hydrates is the position of the heat source: the reactor is located within the hydrate-bearing sediments, thus the heat is generated where it is needed without any losses of energy during transportation. In situ combustion (ISC) and steam-assisted gravity drainage (SAGD) are well-known techniques in the exploitation of unconventional oil deposits such as heavy oil and bitumen reservoirs [6], but in contrast to these already used techniques, the method of in situ combustion introduced in this study is a closed system in terms of a flameless, catalytic oxidation of $\mathrm{CH}_{4}$ within a counter-current heat-exchange reactor without a direct contact between the catalytic 
reaction zone or the reaction products and the reservoir. A catalyst permits a flameless combustion of $\mathrm{CH}_{4}$ with air below the auto-ignition temperature of $\mathrm{CH}_{4}$ in air at $595{ }^{\circ} \mathrm{C}$ and outside of the flammability limits (4.4 vol.\%-16.5 vol.\% in air) [7]. This leads to a double secured application of the reactor with safe operation. The total oxidation of $\mathrm{CH}_{4}$ is an exothermal reaction releasing about $-803 \mathrm{~kJ} / \mathrm{mol}$. Since the decomposition of $\mathrm{CH}_{4}$ hydrates requires about $+52 \mathrm{~kJ} / \mathrm{mol}$ only a small amount of the produced $\mathrm{CH}_{4}$ (about 7\%) has to be consumed for the thermal stimulation using in situ combustion [8]. This study presents the improved design of the counter-current heat-exchange reactor which was developed within the framework of the German national gas hydrate project SUGAR. Recent results from production tests in a pilot plant scale are also presented and discussed.

\section{Results and Discussion}

\subsection{Catalyst Test}

The identification of a catalyst with a high conversion rate of $\mathrm{CH}_{4}$ into $\mathrm{CO}_{2}$ and $\mathrm{H}_{2} \mathrm{O}$ which operates over a long time without significant changes was the aim of this part of the study. Chauki et al. [9] already reported that palladium ( $\mathrm{Pd})$ is suitable as a catalytic active material for the total oxidation of $\mathrm{CH}_{4}$. They observed a conversion rate of $\mathrm{CH}_{4}$ of up to $100 \%$ at temperatures about 475 ${ }^{\circ} \mathrm{C}$. Thus, for this study Pd was also chosen for the first catalyst tests. After preparation and activation of the catalyst (see also Section 3) the catalyst was tested several times within the counter-current heat-exchange reactor for the total oxidation of $\mathrm{CH}_{4}$. In the framework of these tests the catalyst was ignited and preheated with $\mathrm{H}_{2}$ and air until the temperature at the catalyst reached $200{ }^{\circ} \mathrm{C}$. Thereafter, the fuel was changed from $\mathrm{H}_{2}$ to $\mathrm{CH}_{4}$. It turned out that the reaction was stable at $500{ }^{\circ} \mathrm{C}$. Unfortunately, the $\mathrm{CH}_{4}$ conversion only reached $60 \%$. In addition, the $\mathrm{CO}_{2}$ yield decreased whereas the $\mathrm{H}_{2}$ yield increased over time, indicating that the catalyst preferred the partial oxidation of $\mathrm{CH}_{4}$ with time.

Ohtsuka [10] reported in his study that iridium (Ir) and platinum (Pt) are also suitable catalytic active materials for the oxidation of $\mathrm{CH}_{4}$ over $\mathrm{ZrO}_{2}$ supported materials, especially if $\mathrm{Pt}$ and $\mathrm{Ir}$ are combined. Hence, Ir and Pt were also tested in our study as catalytic active material for the total oxidation of $\mathrm{CH}_{4}$. For this, the reactor was loaded with $\mathrm{ZrO}_{2}$-supported $\mathrm{Ir}$ and Pt catalyst particles and tested several times outside of LARS before it was implemented in LARS for the heating and production tests. The catalyst was also ignited with $\mathrm{H}_{2}$ and after changing from $\mathrm{H}_{2}$ to $\mathrm{CH}_{4}$ the temperature of the catalyst immediately reached $450{ }^{\circ} \mathrm{C}$. At this temperature about $99 \%$ of the $\mathrm{CH}_{4}$ were converted. During the first heating (see also Figure 3) and production tests in LARS (see also Figure 5) similar catalyst temperatures and conversion rates could be observed. Unfortunately, the activity and the temperature behavior of the catalyst changed over time. During the ignition and preheating process the temperature increased to $350{ }^{\circ} \mathrm{C}$ instead of $200{ }^{\circ} \mathrm{C}$. When the fuel was changed from $\mathrm{H}_{2}$ to $\mathrm{CH}_{4}$ the temperature slowly increased to $440{ }^{\circ} \mathrm{C}$ and during the production test the reactor could be operated at $486{ }^{\circ} \mathrm{C}$ at the catalyst bed. In addition, the conversion rate of $\mathrm{CH}_{4}$ downgraded to $90 \%$. There was no indication for partial oxidation reaction. After all heating and production tests were performed, the catalyst was removed from the reactor. It turned out that the $\mathrm{Ir} / \mathrm{Pt} / \mathrm{ZrO}_{2}$ catalyst particles interspersed into the aluminum foam were no longer uniformly distributed but mainly situated in the lower part of the aluminum foam close to the gas mixing chamber. Figure 1 shows SEM images 
of the $\mathrm{Ir} / \mathrm{Pt} / \mathrm{ZrO}_{2}$ catalyst after the heating experiments. EDX analyses of the used catalyst material also included carbon signals indicating a slight coking of the catalyst.

Figure 1. (a) $\mathrm{SEM}$ image of several $\mathrm{Ir} / \mathrm{Pt} / \mathrm{ZrO}_{2}$ catalyst particles after the heating experiments; (b) SEM image of one $\mathrm{Ir} / \mathrm{Pt} / \mathrm{ZrO}_{2}$ catalyst particle after the heating experiments. The fine grained material is the $\mathrm{ZrO}_{2}$ support featuring a high surface area.

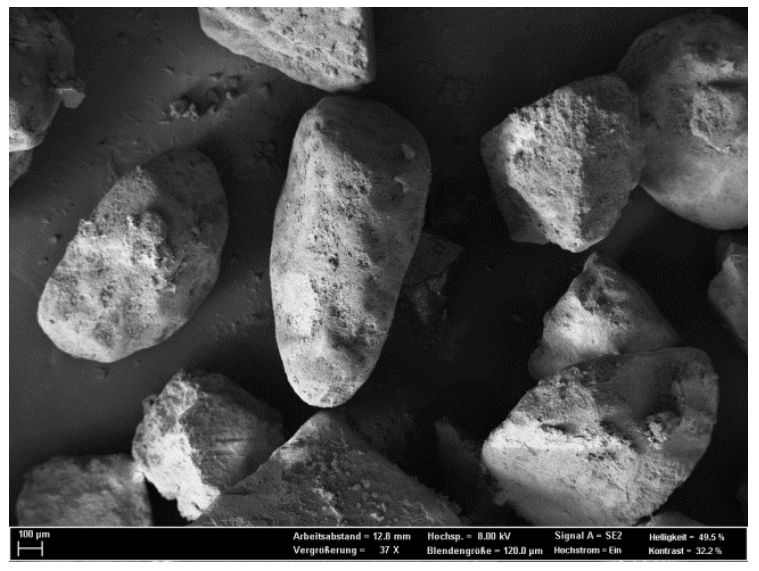

(a)

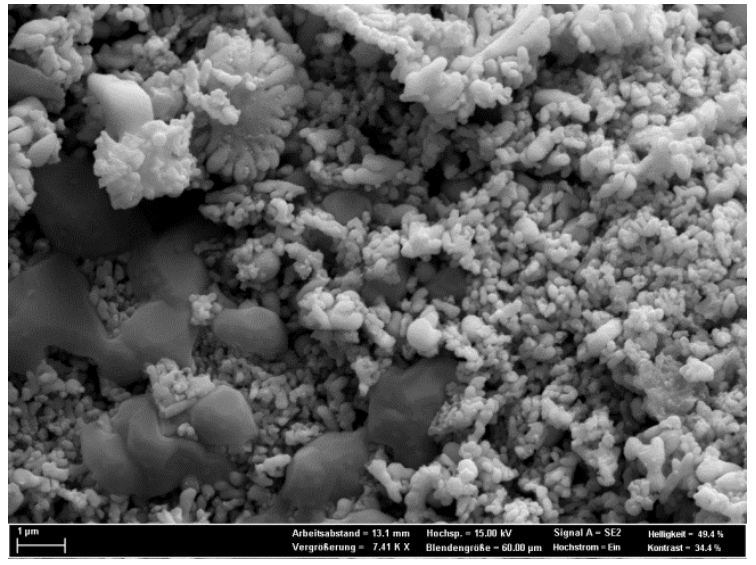

(b)

As a reasonably priced alternative to the noble metal catalyst a universal metal catalyst from UNIFIT KATALYSATOREN GmbH (Engelsbrand, Germany) was tested (see Figure 11). Preliminary results show that the $\mathrm{CH}_{4}$ conversion increases to $99 \%$ at temperatures $>464{ }^{\circ} \mathrm{C}$ (Figure 2). However, the stabilization of the autothermal catalytic oxidation reaction of $\mathrm{CH}_{4}$ at a certain temperature was problematical and has to be improved in further tests.

Figure 2. $\mathrm{CH}_{4}$ conversion over the universal metal catalyst as a function of temperature.

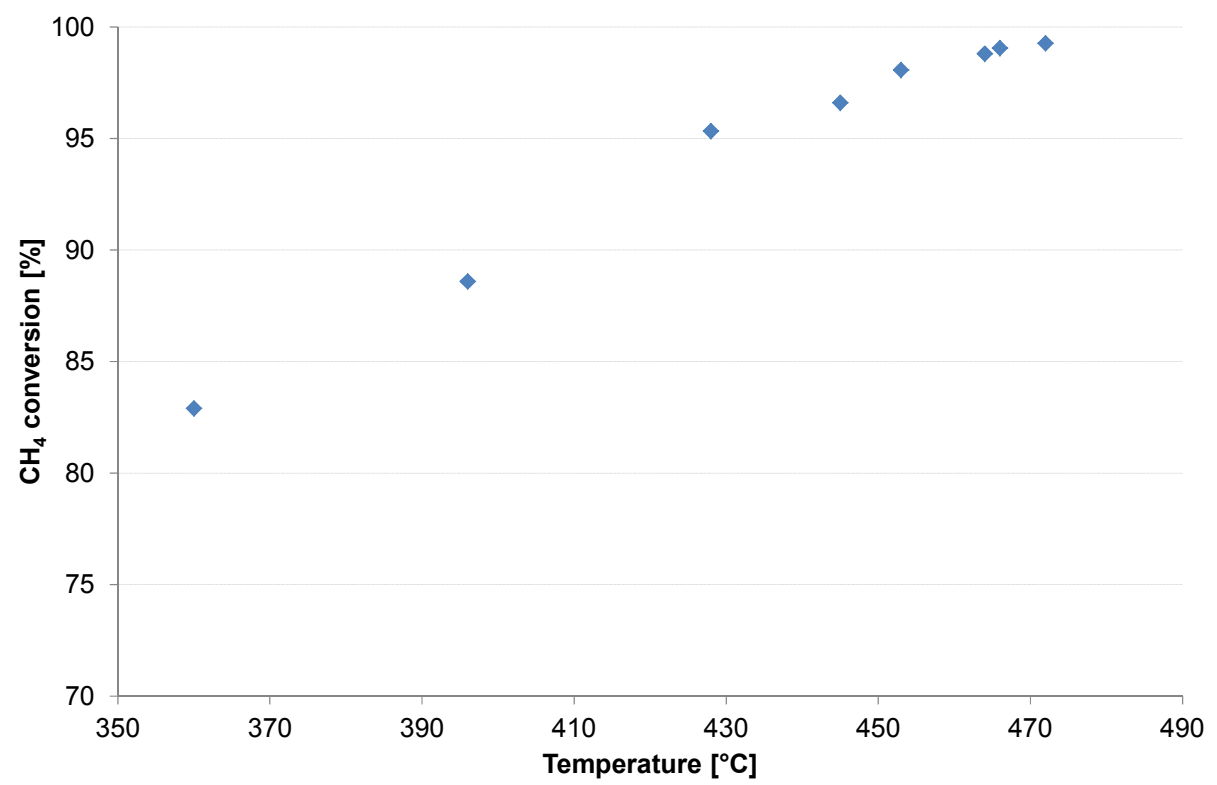




\subsection{Heating and Production Test}

The production test was performed in the LArge Reservoir Simulator (LARS), which has been described in detail elsewhere [2]. The main component of LARS is the pressure vessel which is made of steel and has an inner diameter of $600 \mathrm{~mm}$ and a depth of $1500 \mathrm{~mm}$. This allows the implementation of samples with a diameter of $460 \mathrm{~mm}$ and a length of $1300 \mathrm{~mm}$. The sediment sample is filled into a neoprene jacket which is closed with stainless steel plates at the bottom and top containing the ports for the pore fluid. The top closure additionally contains the lead-throughs for the catalytic reactor and the temperature sensors. Fourteen temperature sensors allow monitoring the temperature distribution in the sediment sample during hydrate formation and thermal stimulation tests. To monitor the pressure distribution within the sediment we additionally installed fourteen 1/16" capillaries situated nearby the temperature sensors which were connected via a switching valve to a pressure sensor outside the pressure vessel. It turned out that because of the low flow rates in our experiments we were not able to resolve any pressure gradients in the high permeable filter sand $(0.63 \mathrm{~mm}-1.00 \mathrm{~mm})$ at hydrate saturations below $60 \%$. Above $60 \%$ all capillaries were always blocked by hydrate so that the pressure monitoring inside the sample was not possible. The complete system can be pressurized up to $25 \mathrm{MPa}$. The confining pressure that acts on the grain framework of the sediment sample via the neoprene jacket is provided by a water-glycol mixture as pressure medium. The hydrate is formed from $\mathrm{CH}_{4}$ dissolved in water in a water saturated sediment sample at $4{ }^{\circ} \mathrm{C}$. The temperature of $4{ }^{\circ} \mathrm{C}$ was chosen to represent hydrate reservoir conditions in nature. For this procedure the pore fluid circulates through the system by sucking brine out of the sample and injecting it into the gas charging vessel through a spray nozzle. $\mathrm{CH}_{4}$ gas continuously dissolves in the brine which flows back into the sample. For the production tests $40 \%-80 \%$ hydrate saturation within sand was achieved. The production test was performed at a pore pressure of $8 \mathrm{MPa}$ and a confining pressure of $12 \mathrm{MPa}$. Before hydrate was formed within the sediment, several heating tests using the heat-exchange reactor were performed in LARS with additional external cooling at $4{ }^{\circ} \mathrm{C}$. Representative temperature profiles within the sediment are depicted in Figure 3. From these tests we learned that the temperature increase in the sediment induces a massive cooling feedback from the cooling system which tried to keep the temperature at $4{ }^{\circ} \mathrm{C}$ constant. Since it is not clear if this behavior represents natural conditions we also performed heating experiments without active external cooling. In this case the cooling liquid may only act as an additional insulation layer to the inner vessel wall, whereas an Armaflex foam insulation at the outer vessel wall efficiently avoids warming effects from the environment. Representative temperature profiles within the sediment during the heating test without external cooling are depicted in Figure 4.

The yellowish part in the diagram shows the temperature profile during the ignition of the catalyst via $\mathrm{H}_{2}$ combustion. $\mathrm{H}_{2}$ was converted until the catalyst reached a temperature of $200{ }^{\circ} \mathrm{C}$ and $350{ }^{\circ} \mathrm{C}$, respectively (see Figures 3,4). Thereafter the feed gas was changed to $\mathrm{CH}_{4}$ instead of $\mathrm{H}_{2}$ (reddish parts in the diagrams). After changing to $\mathrm{CH}_{4}$ an abrupt rise of the temperature at the catalyst to $450{ }^{\circ} \mathrm{C}-500{ }^{\circ} \mathrm{C}$ could be observed. Interestingly, this induced a drop of the measured temperature in the sediment close to the reactor (temperature sensor 9). This behavior could be observed in every heating and production test, regardless if hydrates were present or not (see also Figures 5 and 6). Figures 5-7 show the results of production tests via thermal stimulation using the counter-current heat-exchange reactor with and without external cooling after the $\mathrm{CH}_{4}$ hydrate saturation has reached $40 \%$ and $80 \%$, respectively. 
Figure 3. Left: Temperature profiles versus time for heating experiments using the reactor in sediment + water with external cooling $\left(4{ }^{\circ} \mathrm{C}\right)$. Right: Positions of the temperature sensors within LARS, empty circles show positions of temperature sensors whose profiles are not shown in the left.
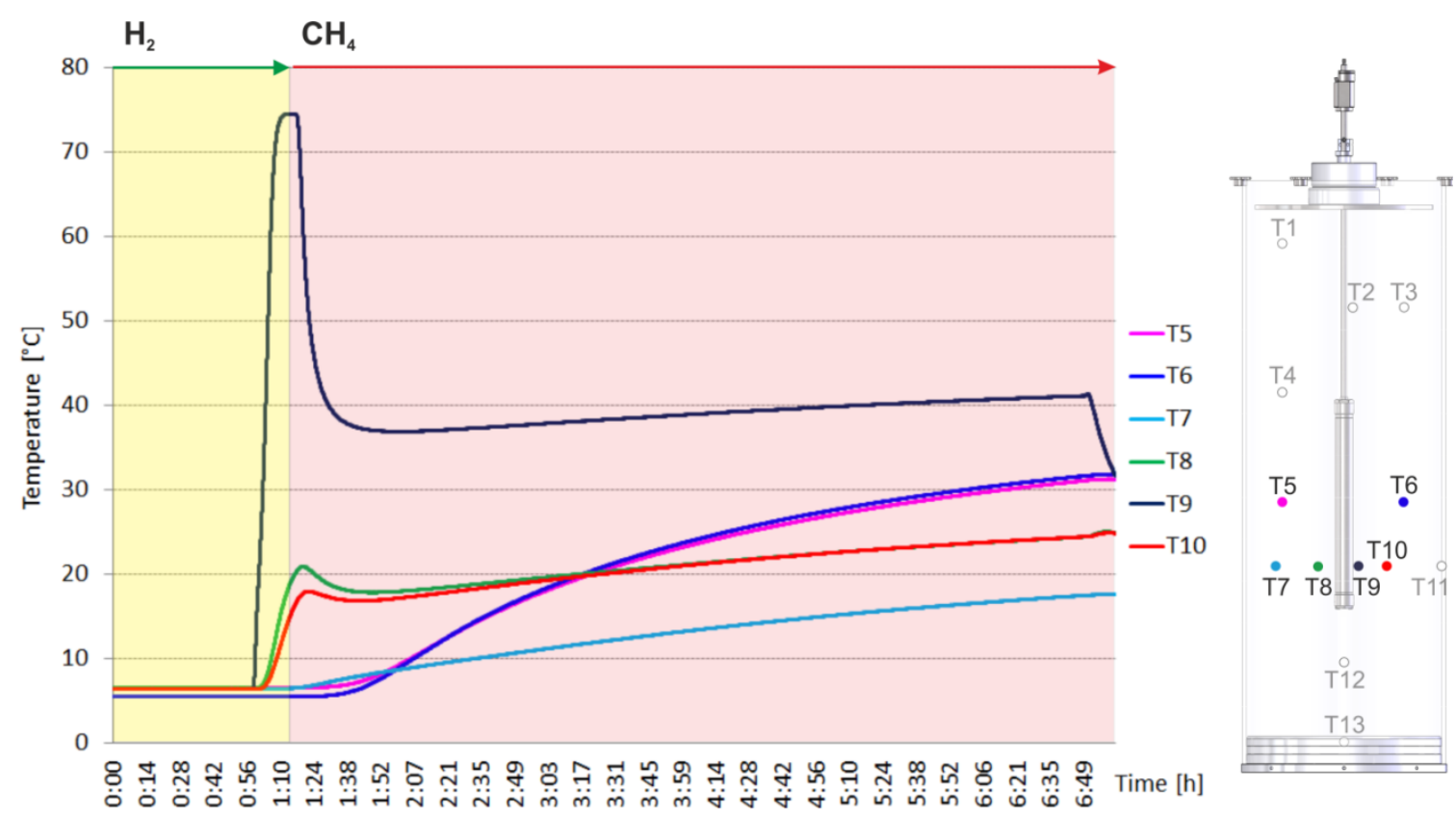

Figure 4. Left: Temperature profiles versus time for the heating experiment using the reactor in sediment + water without external cooling. Right: Positions of the temperature sensors within LARS, empty circles show positions of temperature sensors whose profiles are not shown in the left.
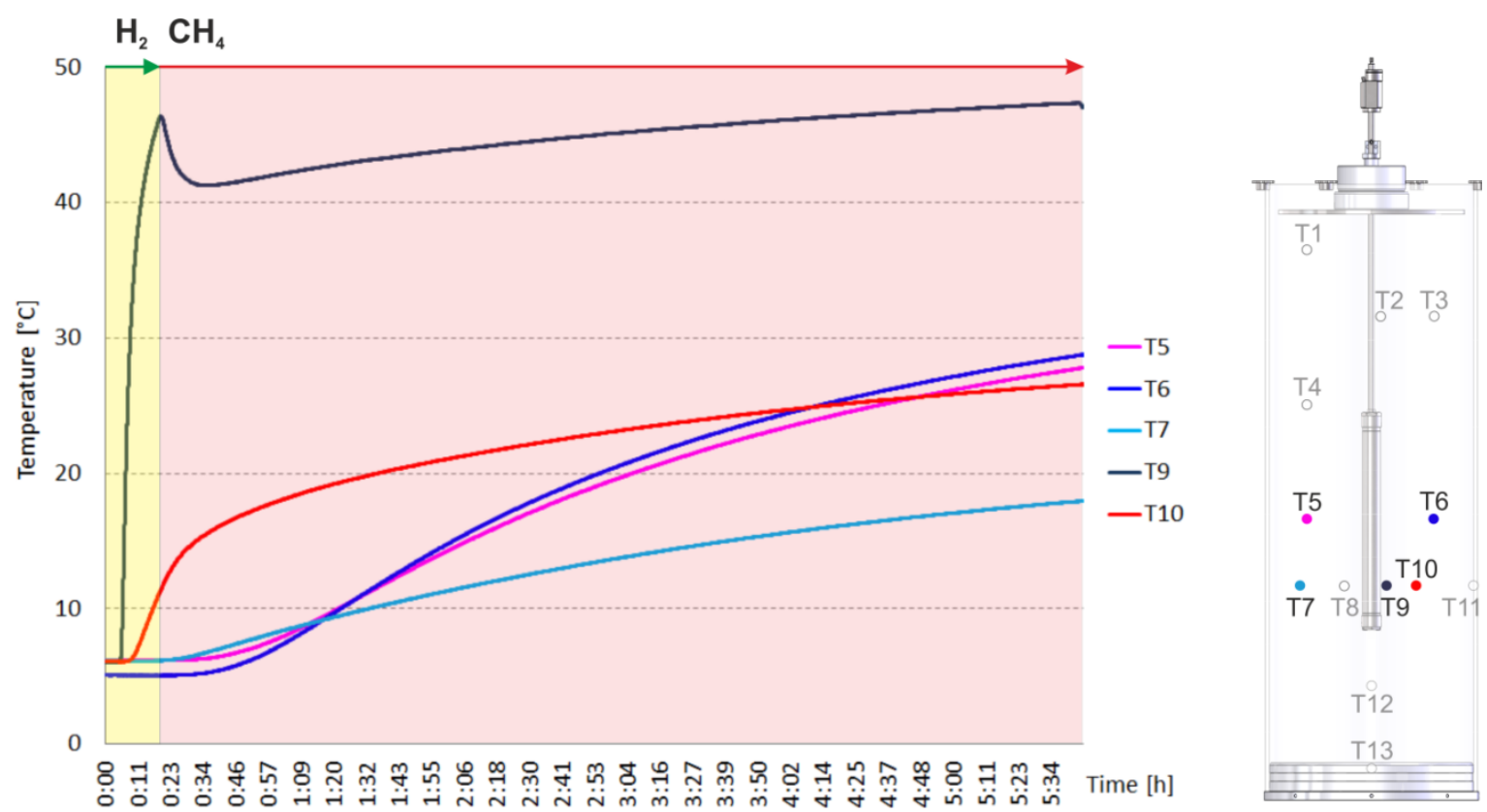
Figure 5. Left: Temperature profiles versus time for production experiments using the reactor in sediment + water + hydrate $(40 \%)$ with external cooling $\left(4{ }^{\circ} \mathrm{C}\right)$. Right: Positions of the temperature sensors within LARS, empty circles show positions of temperature sensors whose profiles are not shown in the left.
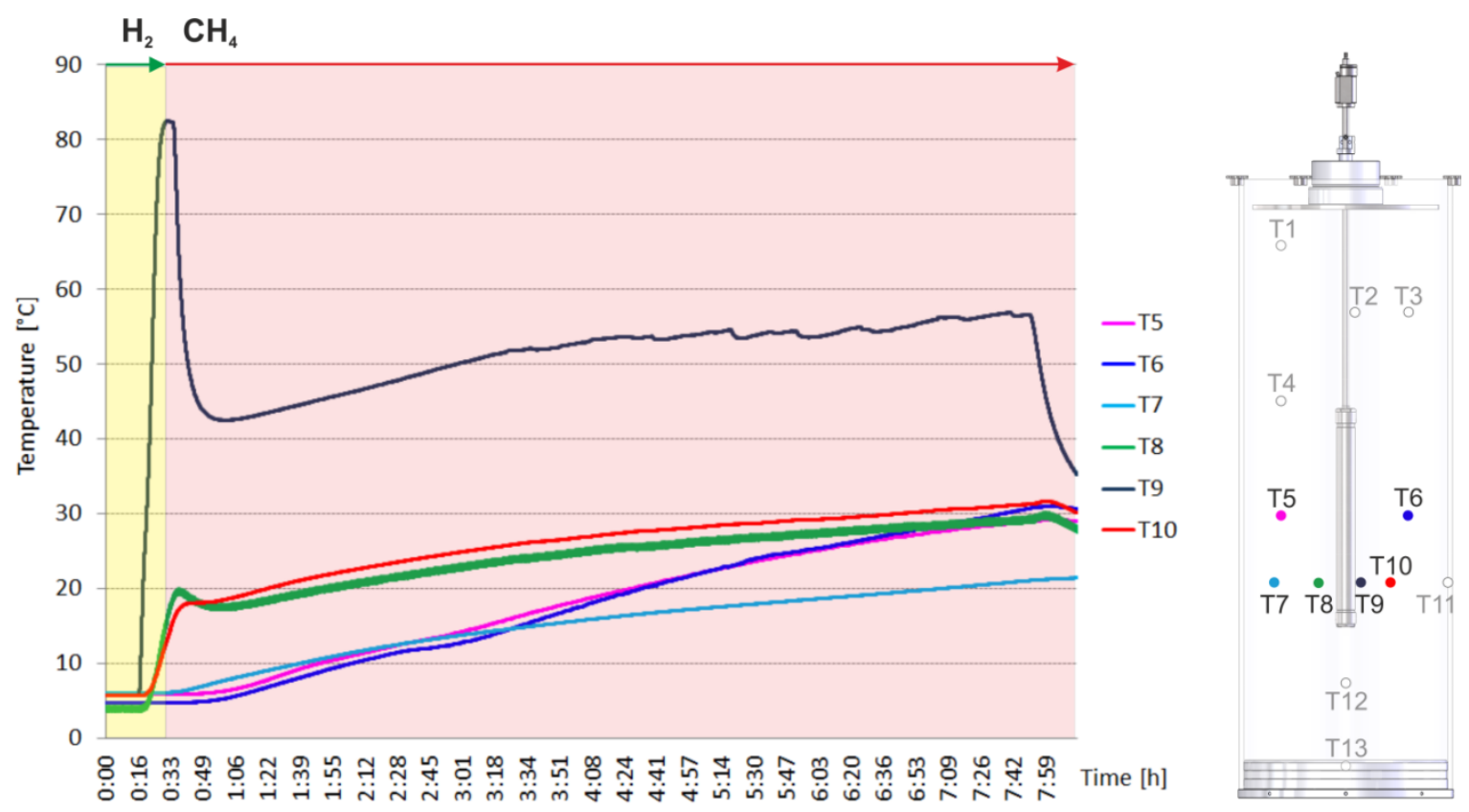

Figure 6. Left: Temperature profiles versus time for production experiments using the reactor in sediment + water + hydrate $(80 \%)$ without external cooling. Right: Positions of the temperature sensors within LARS, empty circles show positions of temperature sensors whose profiles are not shown in the left.

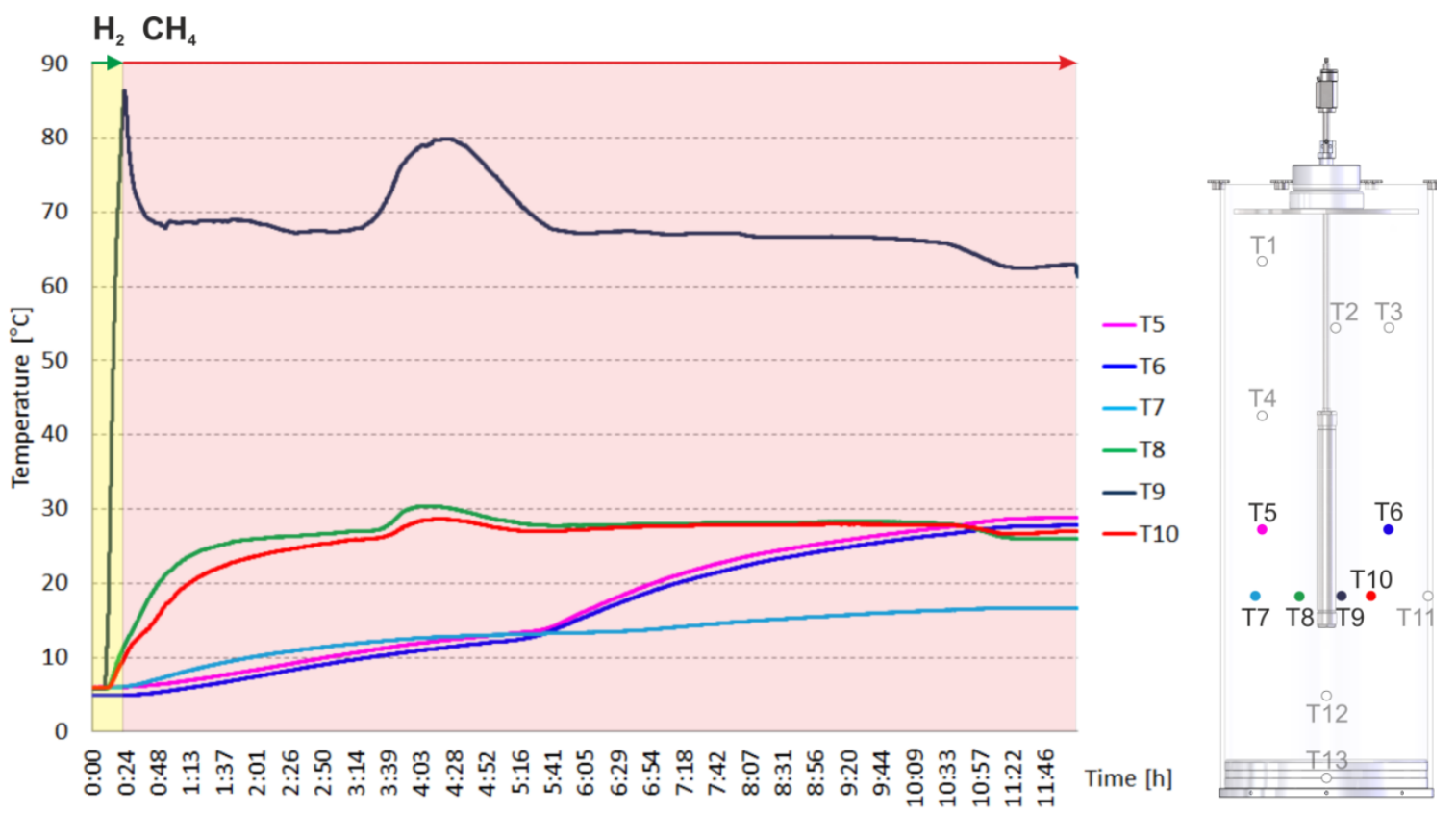


Figure 7. Left: Temperature profiles versus time for heating experiments using the reactor in sediment + water + hydrate $(80 \%)$ without external cooling. Right: Positions of the temperature sensors within LARS, empty circles show positions of temperature sensors whose profiles are not shown in the left.
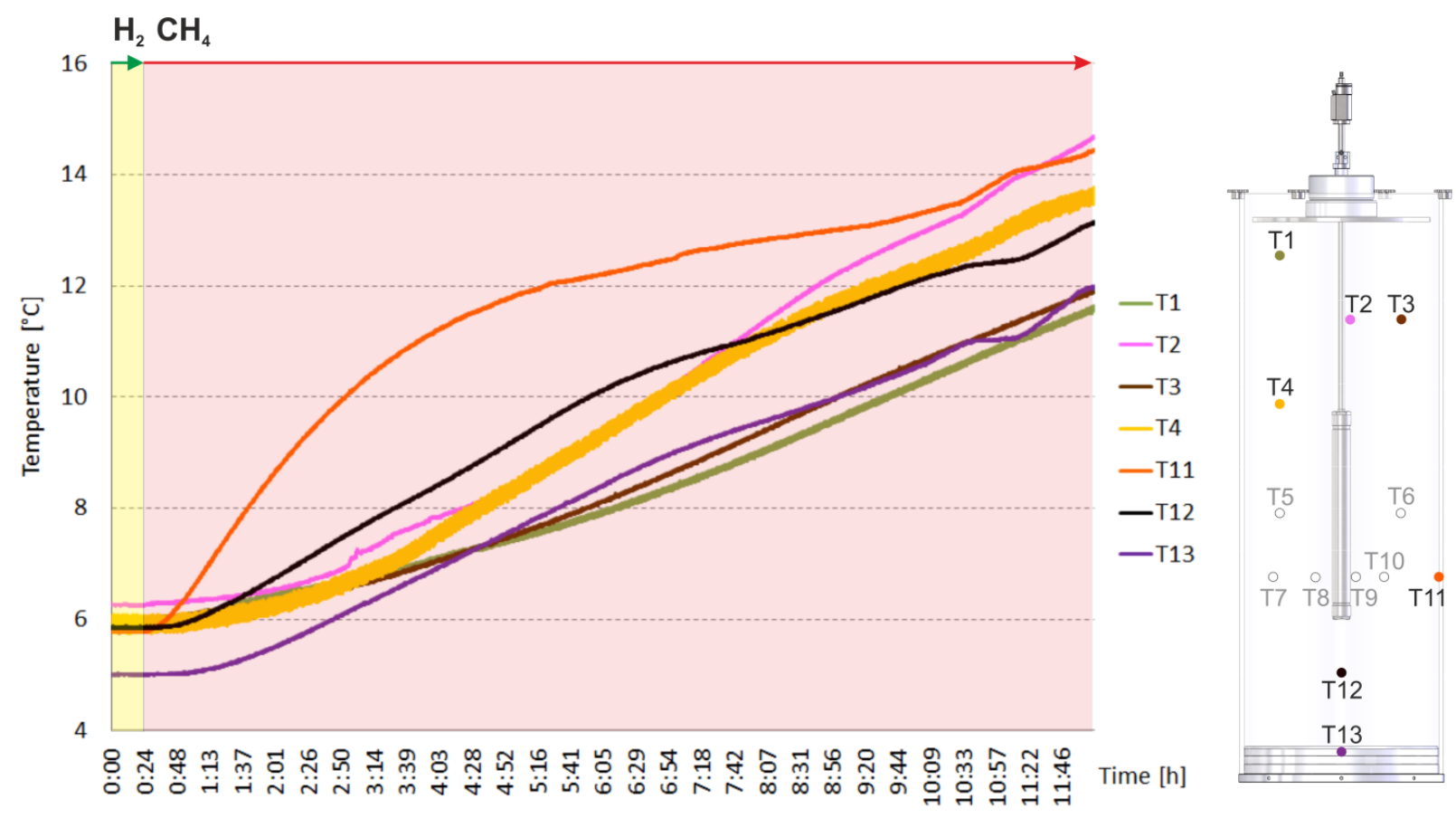

The observed temperature drop in the sediment (see Figure 3-6) may be induced by a convection process: The pore fluid/brine close to the reactor on the level of the catalyst bed starts boiling due to the very high temperatures at the catalyst. The hot fluid rises due to its lower density which results in the movement of colder fluid into the vicinity of the reactor. This process is depicted schematically in Figure 8 b.

In general, the temperature sensors 8 and 10 detect similar increases in temperature which indicates a symmetric propagation of the heat through the sediment. The same is true for temperature sensors 5 and 6 which also detect similar temperature profiles among themselves. Temperature sensor 7 also detects a continuous increase in temperature over time. However, it should be noted that the temperature increases measured at sensors 5 and 6 exceed those measured at sensor 7 although temperature sensor 7 is located closer to the hottest point of the reactor compared to temperature sensors 5 and 6 . This is probably also caused by the convection process described above (see also Figure 8). 
Figure 8. (a) During the ignition of the catalyst using $\mathrm{H}_{2}$ heat is already generated and induces hydrate dissociation in the vicinity of the reactor; (b) When the fuel is changed to $\mathrm{CH}_{4}$ the temperature at the catalyst increases rapidly to $450{ }^{\circ} \mathrm{C}$. The generated heat induces a strong increase of the fluid temperature close to the reactor causing a convection process;

(c) Since the released gas from dissociated hydrates migrates faster through the sediment than the heat front, secondary hydrates form in the colder areas at the top of LARS; (d) After $12 \mathrm{~h}$ the temperatures in almost all areas of LARS were outside the stability field of $\mathrm{CH}_{4}$ hydrate at given pressure.

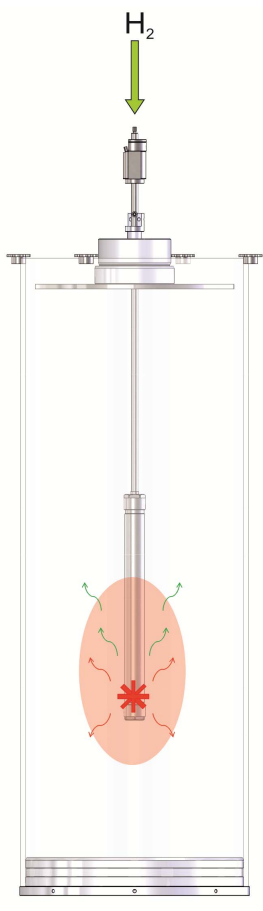

a

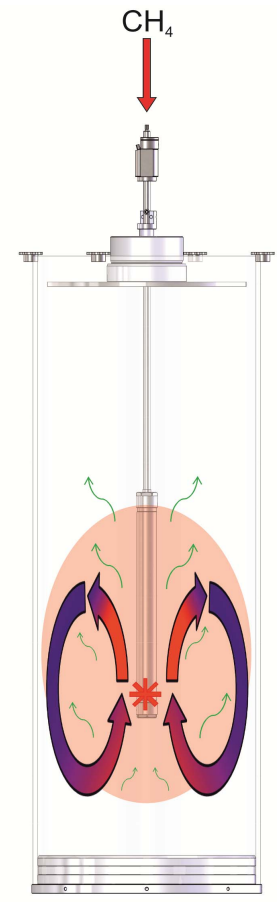

b

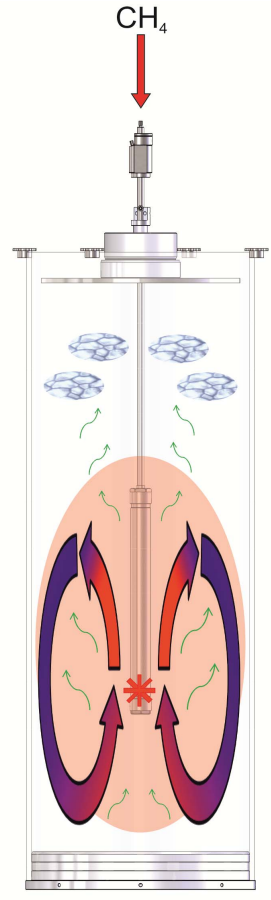

C

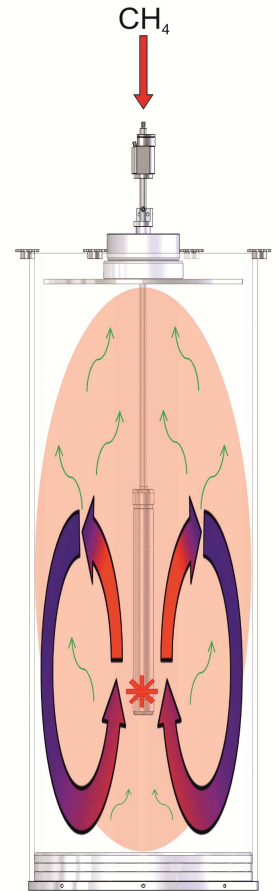

d

Regardless if the sediment is saturated with hydrate or not, all temperature profiles in Figures 3-5 show a continuous increase in temperature over time after the above mentioned temperature drop at the beginning of the heating/production test. However, this is not the case for the temperature profiles shown in Figure 6. The temperature sensors 8, 9 and 10 show an anomalous profile. The irregular temperature increases (bumps) occurring after about four $\mathrm{h}$ of the experiment may be caused by the formation of free gas in the vicinity of the reactor due to hydrate dissociation. The heat conduction of gas is very poor and therefore the heat transport from the reactor into the environment is disturbed resulting in an increase of temperature in the vicinity of the reactor. Since the temperatures decrease again it is very likely that the free gas moved or dissolved. However, in contrast to all other temperature profiles, the temperature profiles of sensors 8, 9 and 10 do not show a further increase. The heat generated by the reactor may be transported or used, e.g., for hydrate dissociation.

Both hydrate production tests show that after approximately $12 \mathrm{~h}$ all sensors detected temperatures equal to or higher than the equilibrium temperature at given pressure, even those which are not located in the vicinity of the reactor (see also Figure 7). This indicates that almost all hydrate within LARS should be dissociated. 
During these first $12 \mathrm{~h}$ of the production test with $80 \%$ hydrate saturation $23.5 \mathrm{~L} \mathrm{H}_{2} \mathrm{O}$ and almost no gas were produced at a constant pore pressure of $8 \mathrm{MPa}$. This indicates that the gas released from the hydrates does not migrate immediately to the production tube which is located in the center of the top of the pressure vessel. However, the 23.5 L represent the fluid expansion due to hydrate dissociation at constant pressure. Since the heat is generated in the middle of the sediment sample and the released gas migrates into the cold region at the top of the autoclave it is most likely that secondary hydrate formation occurs in this area. This is because the gas migrates faster than the heat front propagates inducing a secondary hydrate formation (see also Figure $8 \mathrm{c}$ ). The hydrate might even form a cap above the heating front and impede the upward gas transport to the fluid outlet at the top closure of the setup. In a field experiment the conditions differ: the reactor would be placed in the same borehole which will be used simultaneously for the gas production. Thus, the volume expansion due to the hydrate decomposition would take place into the borehole from which the gas is produced and not within the sediment. Unfortunately, we were not able to locate hydrates within the sediments with imaging techniques; therefore the LARS has been recently equipped with a tomographic system (Electrical Resistivity Tomography-ERT).

However, the data analysis of the previous production experiments showed that despite secondary hydrate formation a fluid expansion of $23.5 \mathrm{~L}$ due to hydrate dissociation was observed. This overall fluid expansion at $8 \mathrm{MPa}$ equates to $1880 \mathrm{~L}_{\text {of }} \mathrm{CH}_{4}$ at $0.1 \mathrm{MPa}$. A detailed description of the pressure dependent fluid expansion effect across the phase boundary of $\mathrm{CH}_{4}$ hydrate was presented by Jang and

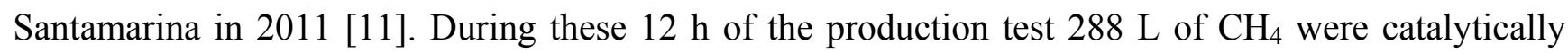
converted to $\mathrm{CO}_{2}$ and $\mathrm{H}_{2} \mathrm{O}$. Thus, about $15 \%$ of the produced $\mathrm{CH}_{4}$ were used for the generation of the necessary heat for the thermal stimulation of the hydrate bearing sediments during the production test.

\section{Experimental}

\subsection{The Counter-Current Heat-Exchange Reactor}

In 2011 we presented a first concept of the counter-current heat-exchange reactor for the thermal stimulation of hydrate bearing sediments via in situ combustion [2]. It turned out that the design of the reactor had to be revised since several weaknesses appeared during the first tests:

- The cold educts $\mathrm{CH}_{4}$ and air flowed separately through a ceramic pipe with two parallel channels. Since the volume of the supplied air is about ten times larger compared to the volume of the supplied $\mathrm{CH}_{4}$, the volumetric flow of both gases in front of the catalyst bed was unbalanced and the mixing of the educts uncompleted. This led to varying combustion of $\mathrm{CH}_{4}$ within the catalyst bed and thus to a spatial unsymmetrically release of heat.

- A ceramic inlay was supposed to protect the outer shell of the reactor which consisted of a Ni-based alloy (ThyssenKrupp VDM) from the heat generated at the catalyst. Unfortunately this ceramic inlay also impaired the heat transfer from the hot product gases to the environment via the reactor wall significantly.

- In general, the heat transfer from the reactor to the environment was poor.

To improve the above named issues the following parts of the reactor design were changed: 
- The cold educts $\mathrm{CH}_{4}$ and air are fed separately through an inner and outer tube made of stainless steel into the reactor. Both tubes end in a nozzle which permits a complete mixing of the educts before entering the catalyst bed.

- The ceramic inlay was removed since the temperatures at the catalyst bed can be controlled by the volume flow of the educts.

- The heat transfer was improved by the embedment of aluminum foam between the inner feed gas tubes and the outer shell.

The new design of the counter-current heat-exchange reactor is shown in Figure 9. $\mathrm{CH}_{4}$ (red) and air (blue) are fed separately through an inner and an outer tube. The mixed gases (purple) flow through the catalyst bed where $\mathrm{CH}_{4}$ and air react to $\mathrm{CO}_{2}, \mathrm{H}_{2} \mathrm{O}$ and $\mathrm{N}_{2}$. The hot product passes the aluminum foam and gives off heat to the reactor shell via the aluminum foam. A cone was placed to trap condensed water.

Figure 9. Design of the counter-current heat-exchange reactor.

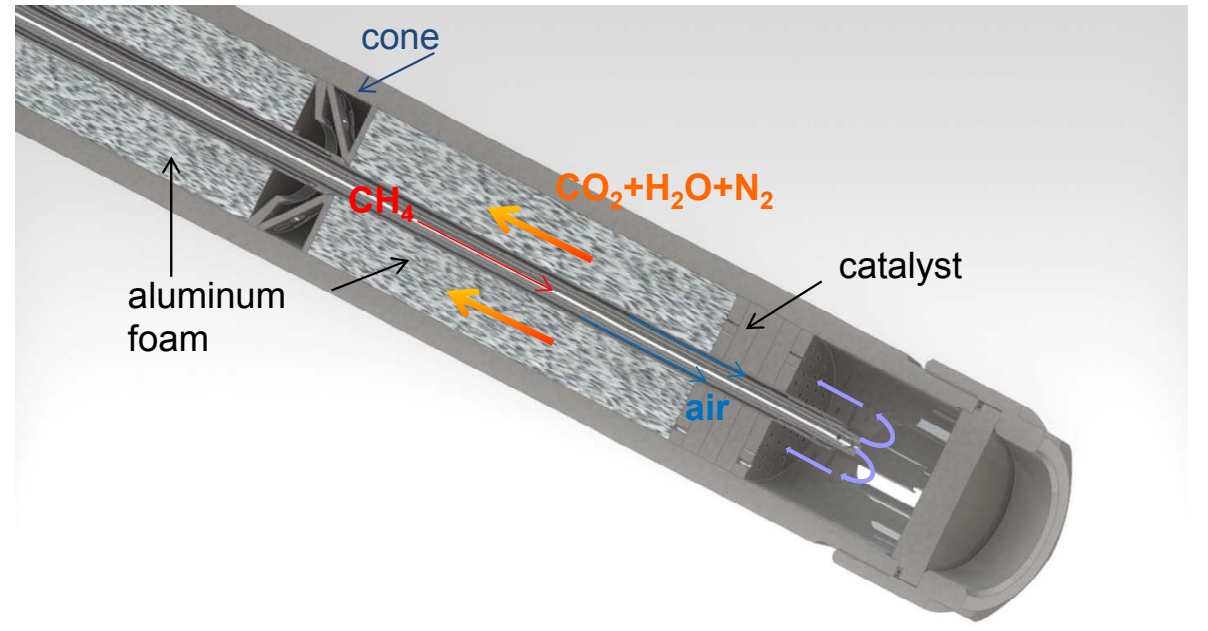

\subsection{The Catalysts}

In their study Chaouki et al. [9] presented the successful conversion of $\mathrm{CH}_{4}$ in a catalytic fixed bed reactor using an industrial catalyst $\mathrm{Pd} / \mathrm{Al}_{2} \mathrm{O}_{3}(0.2 \mathrm{wt} \% \mathrm{Pd})$ with a particle diameter of $2 \mathrm{~mm}-4 \mathrm{~mm}$. Thus, Pd was chosen as one of the catalytic active materials used in this study. The catalyst consists of nominal $10 \mathrm{wt} \% \mathrm{Pd}$ supported on $\mathrm{ZrO}_{2}$ prepared by simple impregnation techniques. For this, the required amount of metal salt (see also Table 1) was dissolved in deionized water resulting in $1 \% \mathrm{Pd}$ in $\mathrm{H}_{2} \mathrm{O}$ and stirred until a clear solution was obtained. Thereafter, $\mathrm{ZrO}_{2}$ powder $(99 \%$, ABCR Dr. Braunagel GmbH \& Co. KG, Karlsruhe, Germany) was added to the solution which was constantly stirred at $90{ }^{\circ} \mathrm{C}$. After $6 \mathrm{~h}$, initially a slurry and later a powder emerged which was subsequently calcinated in flowing air at $300{ }^{\circ} \mathrm{C}$ for $5 \mathrm{~h}$. The catalyst was then pressed to a pellet and broken on a sieve (Ø $1.2 \mathrm{~mm}-1.4 \mathrm{~mm})$. These particles $\left(\mathrm{Pd} / \mathrm{ZrO}_{2}\right)$ were interspersed into the pores of aluminum foam (10 ppi) which acted as a carrier for the catalyst and enlarged the dimensions of the catalyst bed (Figure 10). Iridium (5 wt \% Ir) and platinum (5 wt \% Pt) were also tested as catalytic active materials for the total oxidation of $\mathrm{CH}_{4}$. The preparation of the catalysts was analogous. 
Table 1. Used chemicals for catalyst preparation.

\begin{tabular}{cccc}
\hline Catalytic active material & Metal salt & Purity & Manufacturer \\
\hline Palladium & $\mathrm{Pd}^{\left(\mathrm{NO}_{3}\right)_{2} \times \mathrm{H}_{2} \mathrm{O}}$ & $99.9 \%$ & Alfa Aesar GmbH \& Co KG \\
Iridium & $\mathrm{IrCl}_{3}$ & $99.9 \%$ & Alfa Aesar GmbH \& Co KG \\
Platinum & $\mathrm{H}_{2} \mathrm{PtCl}_{6} 6 \mathrm{H}_{2} \mathrm{O}$ & $99.95 \%$ & Alfa Aesar GmbH \& Co KG \\
\hline
\end{tabular}

Figure 10. Aluminum foam (10 ppi). The catalyst particles (e.g., $\left.\mathrm{Pd} / \mathrm{ZrO}_{2}\right)$ with a diameter of $1.2 \mathrm{~mm}-1.4 \mathrm{~mm}$ were interspersed into the pores of the aluminum foam.

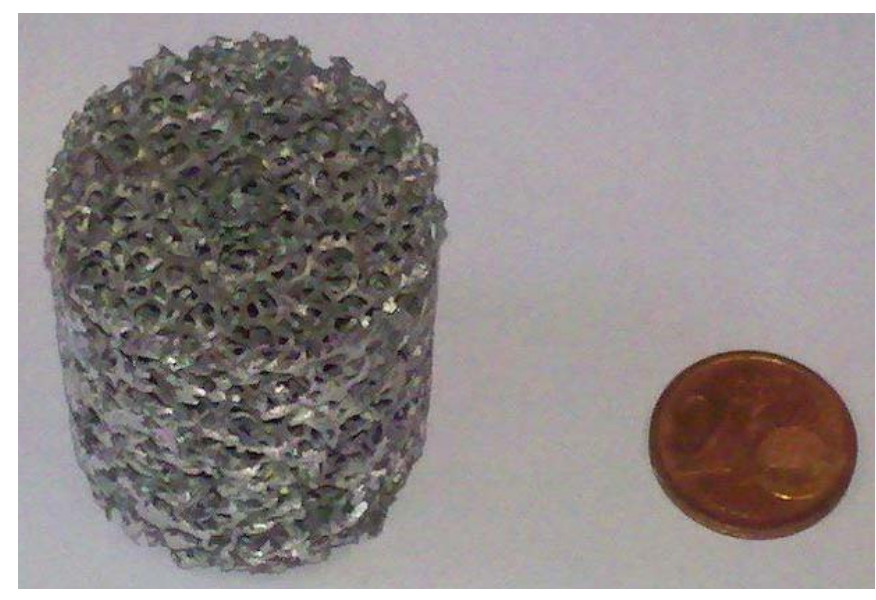

Many catalysts must be activated using special treatments before and/or during their application such as hydrogen reduction to form the catalytic active species [12]. Since these methods were not available the catalyst was activated inside the counter-current heat-exchange reactor under reaction conditions only. Before the $\mathrm{CH}_{4}$ combustion was started, the catalyst was ignited using $\mathrm{H}_{2}$. The fresh catalyst was exposed to temperatures $>225{ }^{\circ} \mathrm{C}$ to ensure a successful ignition of the $\mathrm{CH}_{4}$ combustion. The reaction was running at $500{ }^{\circ} \mathrm{C}$ until conversion and selectivity reached a fairly stable state. Then $\mathrm{CH}_{4}$ was switched off and the heater cooled down in a constant air flow of $2.5 \mathrm{~L} / \mathrm{min}$ for $1 \mathrm{~h}$ to be ready for the next run. To ensure a basic activation of the catalytic system, the described procedure was repeated several times.

In addition to the self-prepared catalysts a commercial universal metal catalyst from UNIFIT KATALYSATOREN GmbH was tested for the total combustion of $\mathrm{CH}_{4}$ in the counter-current heat-exchange reactor. For this purpose, a piece of the catalyst was adapted and placed into the counter-current heat-exchange reactor (see Figure 11). For activation, the catalyst was treated the same way as described above for the self-prepared catalysts. 
Figure 11. Photograph of the universal metal catalyst.

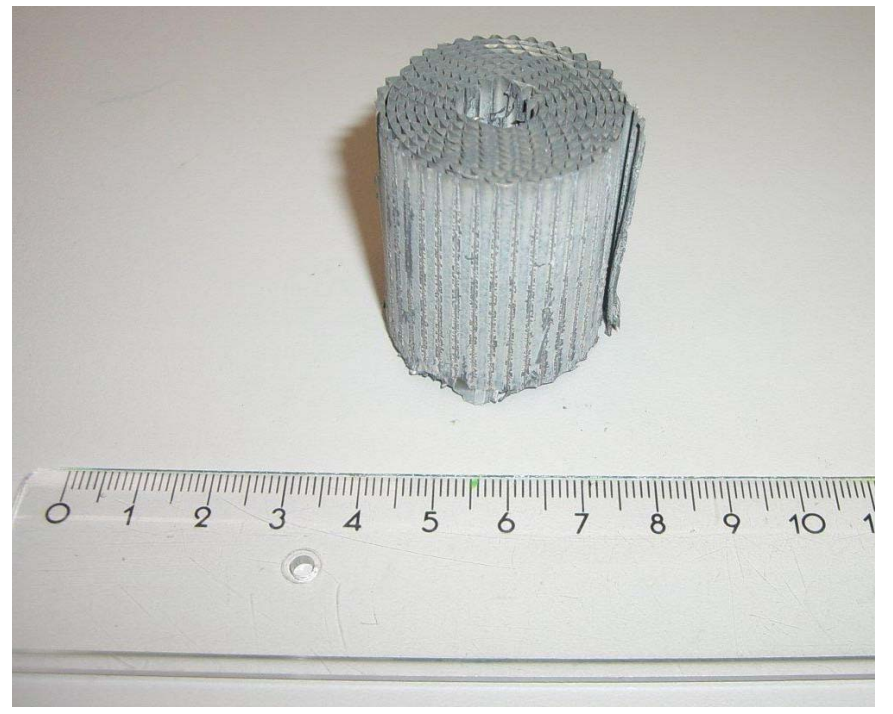

During the reactor test with different catalysts the product gases were analyzed with a quadrupole mass spectrometer (QMS, Prisma QME 200, Pfeiffer Vacuum GmbH, Asslar, Germany) to determine the amounts of $\mathrm{N}_{2}, \mathrm{O}_{2}, \mathrm{CH}_{4}, \mathrm{H}_{2}$ and $\mathrm{CO}_{2}$ of the product gas flow. Based on these data the conversion rates of $\mathrm{CH}_{4}$ were calculated. The SEM images were obtained with a SEM Supra 55 VP from Zeiss (Oberkochen, Germany).

\subsection{The Gas Supply}

In the framework of the laboratory experiments all gases for the catalytic combustion were supplied using gas bottles. The continuous flow of the gases is controlled using a mass flow controller (MFC) for air and a mass flow controller for the fuel gas (Bronkhorst EL-Flow select, AK Ruurlo, the Netherlands). Usually $5 \mathrm{~L} / \mathrm{min}$ of air were fed into the reactor during the ignition and combustion process. The amount of fuel gas was adjusted to the stoichiometric ratio until a constant temperature at the catalyst indicates a stable catalytic reaction. Mass flow of the gases can be controlled using the Bronkhorst FlowView software or manually. For the ignition process and preheating of the catalyst $\mathrm{H}_{2}$ and air were used. After the temperature at the catalyst reached about $200{ }^{\circ} \mathrm{C}$ the fuel gas was changed from $\mathrm{H}_{2}$ to $\mathrm{CH}_{4}$ by shifting the vent manually. Figure 12 shows a sketch of the gas supply for the reactor.

It should be noted that the gas supply of the reactor in a field test can be improved in the way that parts of the produced $\mathrm{CH}_{4}$ gas from the hydrate bearing sediments can be separated and fed into the reactor. 
Figure 12. Sketch of the gas supply for the reactor. Black line = fuel gas $\left(\mathrm{H}_{2} / \mathrm{CH}_{4}\right)$; blue line $=$ air; purple line $=$ exhaust fumes.
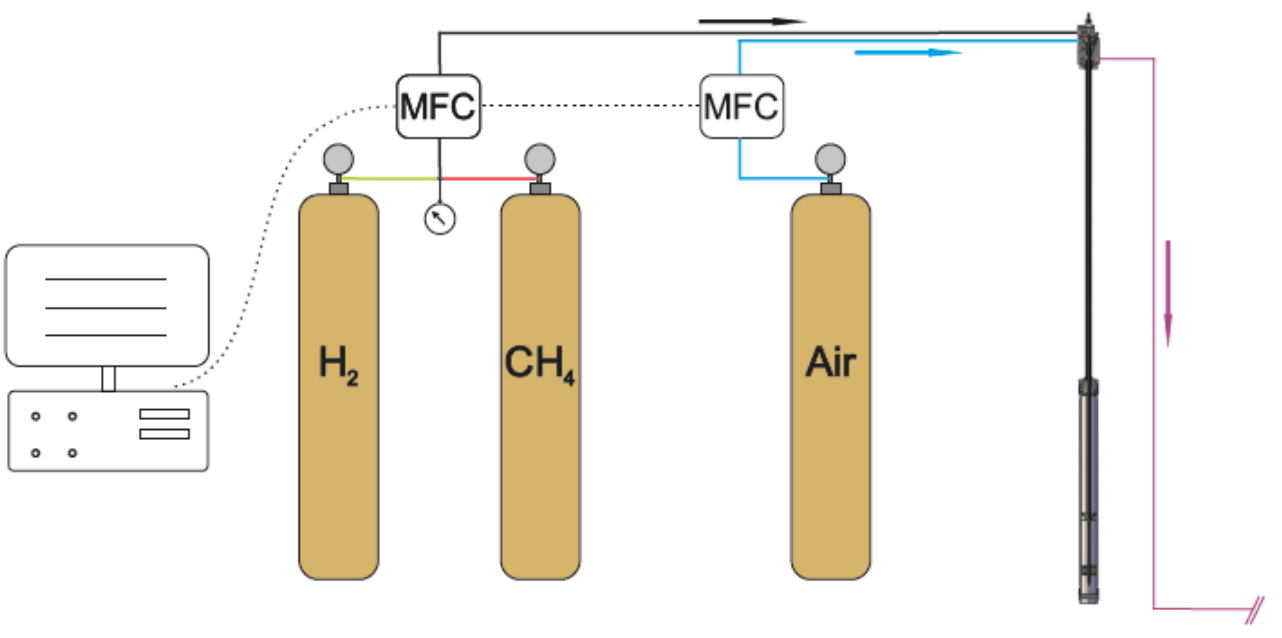

\section{Conclusions}

In the framework of the German joint project SUGAR a counter-current heat-exchange reactor designed to decompose gas hydrates in sediments via thermal stimulation was developed. The heat is produced via the catalytic oxidation of $\mathrm{CH}_{4}$. To optimize the heat transfer into the sediment the design of the reactor was improved by employing aluminum foam. To enhance the catalytic reaction different self-prepared catalysts were tested. It turned out that $\mathrm{Pt} / \mathrm{Ir}$ supported on $\mathrm{ZrO}_{2}$ shows the highest $\mathrm{CH}_{4}$ conversion rate $(>99 \%)$ running stable at $450{ }^{\circ} \mathrm{C}$. The catalysts were also applied for the production test in the LArge Reservoir Simulator LARS. Also the universal metal catalyst showed promising conversion rates and is a possible, low-cost alternative. The efficiency of the thermal stimulation method via in situ combustion seems to be promising: The production tests showed that about $15 \%$ of the produced $\mathrm{CH}_{4}$ were used for the generation of the necessary heat for the thermal stimulation of the hydrate bearing sediments. We also learned from these tests that the gas migration processes within the sediments are complex and could not be clarified with the existing temperature sensor net in LARS. Further research is necessary using tomographic systems.

\section{Acknowledgements}

The German Federal Ministry of Economy and Technology provided funding for this work through Research Grant 03SX250E. The authors thank the team of the GFZ high pressure machine shop for the technical support and Bernd Steinhauer for the preparation of the catalyst during the first period of the SUGAR project.

\section{Conflicts of Interest}

The authors declare no conflict of interest. 


\section{References}

1. Cranganu, C. In-situ thermal stimulation of gas hydrates. J. Pet. Sci. Technol. 2009, 65, 76-80.

2. Schicks, J.M.; Spangenberg, E.; Giese, R.; Steinhauer, B.; Klump, J.; Luzi, M. New approaches for the production of hydrocarbons from hydrate bearing sediments. Energies 2011, 4, 151-172.

3. Sloan, E.D.; Koh, C.A. Clathrate Hydrates of Natural Gases, 3rd ed.; CRC Press Taylor and Francis Group: Boca Raton, FL, USA, 2008.

4. Kvenvolden, K.A.; Lorenson, T.D. The Global Occurrence of Natural Gas Hydrates. In Natural Gas Hydrates-Occurrences, Distribution, and Detection; Paull, C.K., Dillon, W.P., Eds.; American Geophysical Union: Washington, DC, USA, 2001; pp. 3-18.

5. Yasuda, M.; Dallimore, S. Summary of the methane hydrate second mallik production test. J. Jpn. Assoc. Pet. Technol. 2007, 72, 603-607.

6. Yang, X.; Gates, I.D. Design of hybrid steam - In situ combustion bitumen recovery processes. Nat. Resour. Res. 2009, 18, 213-233.

7. Air Liquide. Downloadable Material Safety Data Sheet (MSDS) for $\mathrm{CH}_{4}$; Air Liquide: Paris, France, 1966.

8. Rydzy, M.B.; Schicks, J.M.; Naumann, R.; Erzinger, J. Dissociation enthalpies of synthesized multicomponent gas hydrates with respect to the guest composition and cage occupancy. $J$. Phys. Chem. B 2007, 111, 9539-9545.

9. Chaouki, J.; Sapundzhiev, G.C.; Kusohorsky, D.; Klvana, D. Combustion of methane in a cyclic catalytic reactor. Ind. Eng. Chem. Res. 1994, 33, 2957-2963.

10. Ohtsuka, $\mathrm{H}$. The oxidation of methane at low temperatures over zirconia-supported $\mathrm{Pd}$, Ir and Pt catalysts and deactivation by sulfur poisoning. Catal. Lett. 2011, 141, 413-419.

11. Jang, J.; Santamarina. J.C. Recoverable gas from hydrate-bearing sediments: Pore network model simulation and macroscale analyses. J. Geophys. Res. 2011, 116, B08202.

12. Lyubovsky, M.; Pfefferle, L. Methane combustion over the $\alpha$-alumina supported Pd catalyst: Activity of the mixed Pd/PdO state. Appl. Cat. A 1998, 173, 107-119.

(C) 2013 by the authors; licensee MDPI, Basel, Switzerland. This article is an open access article distributed under the terms and conditions of the Creative Commons Attribution license (http://creativecommons.org/licenses/by/3.0/). 